\title{
Analysis of Enterprise Marketing Innovation Level and Path Based on Big Data Perspective
}

\author{
Yiqiang Han* \\ School of Business Administration \\ Jiangsu Vocational Institute of Commerce \\ Nanjing, China \\ yiqianghan@163.com
}

\begin{abstract}
This paper aims to help companies explore the level of marketing innovation in the era of big data and build a path for marketing innovation from a big data perspective. With the advent of the Internet and the era of big data, many data technologies have been applied and promoted. In this context, enterprises will not only face the opportunity of development but also face more intense market competition. Therefore, in order to improve the efficiency and effectiveness of marketing activities, companies need to carry out marketing innovation. The article analyzes the marketing innovation path from the three levels of concept layer, technology layer and application layer, puts forward the idea of changing marketing concept, perfecting technical support and applying new marketing method and expounds the innovation of enterprise marketing based on the perspective of big data.
\end{abstract}

Keywords—big data; marketing; analysis; innovation

\section{INTRODUCTION}

The growth and development of an enterprise is inseparable from marketing activities, effective marketing activities need to accurately grasp the behavior and characteristics of consumers, fully tap the needs of consumers, and accurately deliver marketing information. To accomplish these tasks, it must be established on big data analysis and support. At the same time, entering the era of big data, enterprises combined with their own characteristics, make full use of big data technology, and innovative marketing strategies, it will also enhance the competitiveness of enterprises. Therefore, it is very necessary for enterprises to study marketing activities and analyze their innovation paths from the perspective of big data.

\section{THE CONCEPT AND CHARACTERISTICS OF BIG DATA}

Wikipedia defines "big data" often referred to as massive data, large data, or massive data. It usually means that the data capacity involved is so large that it cannot be intercepted, managed, processed manually in a reasonable amount of time and organized the information that humans can interpret. Regardless of the concept, in summary, "big data" has the following four basic characteristics: the volume of data is very large, the data types are complex, the value density of data is low and the processing speed of data is fast. The industry's general big data $4 \mathrm{~V}$ feature is summarized as Volume, Variety, Value, and Velocity.
With the advent of the era of big data, the impact of big data on human society is becoming more widespread. Enterprises face a new competitive environment in their business management activities, many companies or individuals are affected by big data analysis. In order to carry out marketing activities and develop marketing strategies in the era of big data, enterprises must innovate traditional marketing in combination with big data and use big data to mine various valuable commercial information that can be utilized [1].

\section{THE CONNOTATION OF MARKETING INNOVATION}

In the late 1930s, the economist Joseph Alois Schumpeter first mentioned the theory of innovation in his book "The Theory of Economic Development". Based on the foundation of theoretical and technological changes for the unbalanced growth of the economy, he believes that the intrinsic factor of economic development is innovation, which is to bring a new combination of production factors and production conditions that have never been seen before into the existing production system. The mission of economic development is to "implement a new combination." This "new combination" encompasses many forms, including new technologies, new markets, new products, and new sources of raw materials. In the mid-20th century, with the continuous development of the new technological revolution, the limitations and constraints of the original neoclassical economics were gradually broken, innovative research gradually evolved into specialized research on innovation effects and internal processes. In the 1970s and 1980s, innovation research began to be relatively independent from the scope of economic development cycle research and management science. Under such a background, the theoretical system of innovation research was initially formed. In 1986, Peter F.Drucker further elaborated on innovation from both supply and demand: from a supply perspective, innovation is a change in the output of a vendor's resources; from a demand perspective, innovation is a change in the value and satisfaction to consumers. From the early 1980s to the present, the state of innovation research shows a comprehensive development, focusing on the content of its research and the guidance of the results on human society, business economy and technological activities. From the perspective of the core of innovation, the important feature of innovation is social value. From the perspective of marketing to analyze the value, innovation should bring benefits to both enterprises and consumers, that is, innovation should fill the gap between products created by 
enterprises and consumers demand. Economists have called sustainable innovation as "the sixth discipline" of enterprises and innovation is also an important embodiment of the core competitiveness of enterprises in the market. Therefore, the connotation of marketing innovation means that enterprises should change certain elements of marketing activities according to the changes of internal and external environment, combine their own resource conditions, establish new value for consumers and enterprises based on the needs of consumers, weaken competitors and achieve the company's own marketing goals.

In the era of big data, enterprise marketing innovation research is based on the use of big data mining technology, analyzes marketing activities and innovate marketing channels, marketing methods and marketing models so that all aspects of corporate marketing management activities, from decision to implementation, become more controllable and precise.

\section{PROBlEMS FACED BY CORPORATE MARKETING IN THE ERA OF BIG DATA}

\section{A. Consumers are increasingly controlling the outcome of} the marketing process

In the product-centric marketing 1.0 era, because of the era of the seller's market, the business data or information held by consumers is very limited; the results of the marketing process are often controlled by the seller. The 1.0 era is the era of product management as the core, without the embodiment of consumer personality, as Ford Motors claimed, "No matter what color car you need, Ford only has black."

With the development of the global economy and the increasing enrichment of products, the market has gradually entered the buyer's market since the 1970s; the customercentric marketing 2.0 era is coming. Enterprises pay more and more attention to consumers and begin to focus on market segmentation, target market and positioning. With the development of media and communication, consumers have increased their understanding of business data and information, their influence on corporate marketing effectiveness has also increased.
Since the 1990s, with the popularity of Internet and mobile communication applications, information is no longer a scarce resource. People can get a lot of data and information anytime and anywhere, human society presents a highly interconnected state. Consumers have an extremely convenient and independent opportunity to express themselves and share information anytime and anywhere, all these action make a strong influence on the results of the corporate marketing process [2]. In the 2.0 era, the customer-centric traditional market positioning model is difficult to continue to create demand. Enterprises need to pay more attention to the inner and emotional needs of consumers, this is the marketing 3.0 era in the context of big data. With the marketing era evolved from 1.0 to 3.0, more and more business information is being grasped and becoming easier to be obtained by consumers due to data changes so that consumers become more and more powerful in control and influence aspect in the evolution of the marketing process. This is a problem that companies have to face in the context of the era of big data.

\section{B. Consumer cognitive evolution makes the decision-making process more complicated}

Before the marketing 3.0 era, the main way for consumers to obtain information and data came from advertising and personnel recommendation. Consumers have limited access to information and data and the process is relatively simple when making consumer decisions. In the era of big data, consumers have access to a wide range of data and information channels. As shown in Fig. 1, in addition to accurate advertising, consumers can also know the experience and evaluation of others through social sharing, mine information through spontaneous search and experience products and services by participating in brand interactions [3]. It is precisely because of the evolution of consumer cognition in the era of big data that their consumption decisions can perceive a large amount of information when experiencing contact, consideration and evaluation, which determines the decision-making process of consumers, is more complicated.

Contact

Consideration

Evaluation

Purchasing

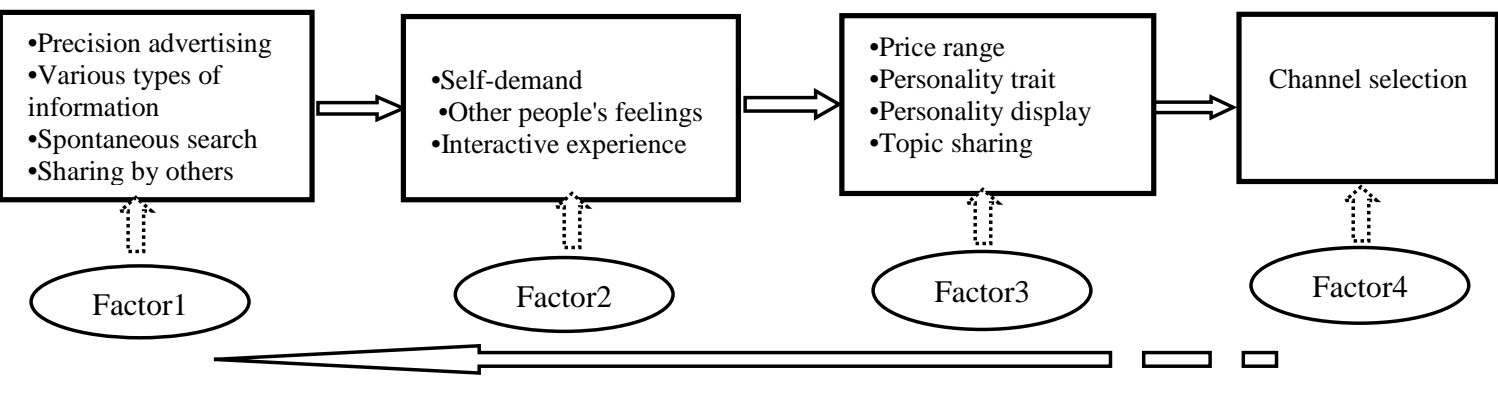

Information feedback

Fig. 1. Consumer decision-making process under multiple factors 


\section{The development of technology has changed the behavior habits of consumers}

Today's enterprises are in the era of rapid development of the Internet and massive data. With the popularity of the Internet and mobile communication tools, various applications such as social software and APP have become friends in the consumer life. According to the data, as of September 2018, Facebook announced that it has an average of 300 million active users per day. The number of active users of WeChat that are widely used in China has reached 1.08 billion per month with an average of 45 billion messages sent per day. Technology has changed the life and also changed the behavior habits of consumers. Consumers have changed from the role of passively accepting information to the participants and promoters of marketing activities. The information contacted and released by consumers are huge. Many consumers use tools such as the Internet, WeChat and LBS (location-based services) to acquire and understand product information. This requires that corporate marketing activities in the era of big data cannot ignore changes in consumer behavior.

\section{ANALYSIS OF ENTERPRISE MARKETING INNOVATION BASED ON BIG DATA PERSPECTIVE}

In traditional marketing 2.0, many companies rely on production technology, concept packaging, media promotion and strong execution of channels to sell products to achieve marketing goals. However, in the context of big data, the openness of information and the diversification of consumer information acquisition channels make consumers have more right to know and control. The effects and results of corporate marketing activities are difficult to achieve under traditional marketing models [4]. Based on the foundation of big data, innovative enterprise marketing has become an inevitable trend.

\section{A. The level of enterprise marketing innovation in the era of} big data

Enterprise marketing innovation needs to be carried out at three levels. The first level is the innovative marketing concept, called the idea layer innovation. In the era of big data, consumers' individualized needs, information acquisition and utilization levels and diversification of information sharing methods require enterprises to pay attention to consumers emotions, pay attention to consumers' experiences, to strengthen customer relationship management. Enterprise marketing concepts and ideas must integrate experience marketing, relationship marketing, green marketing and cooperative marketing. The second level makes full use of relevant technologies in the era of big data, improves computer information systems and helps enterprises effectively carry out marketing activities, which is called technology layer innovation. The third level refers to the specific methods of marketing work, such as how to use the event marketing to carry out the marketing promotion, etc., which is called application layer innovation. In the context of big data, the enterprise's marketing ecosystem is accompanied by a large amount of data every day. The size of the data varies; the shape of the data has both structural and non-structural data; some value of the data is dominant and other is hidden; different values need to be tapped. The data is transmitted and updated extremely quickly, showing a strong dynamic. With the further development of science and technology such as the Internet, cloud computing and big data, the three levels of corporate marketing innovation will also be enriched and deepened.

\section{B. The path of enterprise marketing innovation from the perspective of big data}

The arrival of the era of big data has accelerated the scientific process of marketing. The emergence of massive data and the maturity of data analysis and mining technology have provided a guarantee for the scientificization of enterprise marketing decision analysis. Through the quantitative calculation and analysis of complex and diverse marketing behaviors, we can find out the correlations beyond the experience in the marketing activities so that the marketing work of the enterprise can get rid of the traditional marketing model with the sample traceability and avoid the entry into the marketing misunderstanding and hereby win the opportunity of market competition. Starting from the enterprise marketing innovation hierarchy, the path of enterprise marketing innovation needs to be carried out and implemented through the concept layer, technology layer and application layer.

1)Reconstruct the value thinking of enterprise marketing: After entering the era of big data, human society has changed its internal and external environment. The concept, technology and application of corporate marketing have changed. The marketing of enterprises has entered the 3.0 era. Only by combining the characteristics of the big data era and reconstructing the value thinking of enterprise marketing, can we innovate marketing activities from the concept level of corporate marketing and gain the strategic height of market competition. For today's enterprises, there are two most important values of thinking, one is Internet thinking and the other is humanistic thinking.

a) Internet thinking: From the perspective of big data, companies need to re-examine the entire business environment and marketing ecology. The innovation of marketing concepts requires "Internet +". The value thinking of enterprise marketing should first be "Internet thinking", which also reflects the re-examination and reflection of the entire business ecosystem of the market, consumers, products/services and value chains in the context of big data and cloud computing. To establish corporate Internet thinking, we must grasp the core connotation of Internet thinking, which is also the value of Internet thinking. The core connotation of Internet thinking is reflected in the following aspects:

- User-centric: Enterprises stand on the "user-centric" perspective to examine problems, think about and improve all aspects of the business value chain and deeply understand users; this is the most important connotation of Internet thinking. In short, getting the user's approval can win a contract for the company. Since the production and lifestyle of human society are being changed by Internet technology, if there is no clear understanding of this development trend, the strategic decision of enterprises in the business ecology may 
face great risks. The essence of "user-centered" thinking is to pay attention to the user's experience and feedback, so that information can be transmitted efficiently and smoothly between users and enterprises, so that the enterprise establishes an error correction mechanism to track user feedback and forms an innovative standardization system internally to accelerate the product update cycle.

- Thinking with data: The era of big data has reshaped the understanding of assets and key competitive factors. The data generated by users generally reflects the three levels of information, behavior and relationship. Using data to analyze and think helps enterprises to make business predictions and decisions more precise.

b) Humanistic thinking: Humanity is the core part of human culture and the cornerstone of the cultural spirit of the healthy development of human society. Its core idea is to care and respect for people. Corporate humanistic thinking has three aspects in marketing innovation:

-Build a "strong ties" with internal and external customers: As we all know, the theory of interpersonal relations proposed by American sociologist Mark Granovetter divides the network of interpersonal relationships into "strong ties" and "weak ties." "Strong ties" refers to the strong homogeneity of the individual's social network. This homogeneity makes the relationship between people and people become close by strong emotional factors. To succeed in social competition, companies need the common value of internal customers (employees) and external customers. Enterprise management with humanistic thinking values attaches' importance to "strong relationship" with internal and external customers, establishes a good image of its own brand and ensures the possibility of achieving the purpose of corporate marketing activities.

- Create an "empathy" for customers: The mutual trust between enterprises and customers is a problem facing the needs of modern business ecology. Due to the unfair phenomena such as corporate dishonesty, product safety and consumption traps in the commercial society, customers have a habit of "habitual suspicion" about the words and deeds of enterprises, and enterprises must focus on In the construction of the "empathy of the customer", put yourself in the position of the customer, establish a humane atmosphere and business ethics that respect the customer and care for the customer, and eliminate the "habitual suspicion" of the customer. Through empathy, all relevant parties in the business value activities can share the value and build the foundation for the sustainable development of the company and customers.

- Improve customer perceived value: When today's commercial society is increasingly showing the phenomenon of homogenization of products, homogenization of services and homogenization of technology, thinking and satisfying of the customer's spiritual level appeal and enhancing the "spiritual value" in humanistic thinking will give full play to the differences and uniqueness of corporate marketing activities and greatly enhance the perceived value and identity of customers.
2) Improve technical support for corporate marketing: The technological revolution in the era of big data has produced a large number of new technologies. Enterprises have more choices in implementing big data collection, storage, processing and display. The application of these new technologies guarantees the innovation of corporate marketing activities and improves corporate customers' perception of business experience and marketing value. For example, IBM's InfoSphere Big Data Analytics platform, as a comprehensive information integration platform, includes information integration, data warehousing and analysis, master data management, data security and privacy and lifecycle management, which accelerates the speed of value realization of enterprises and improves information quality [5]. In addition, the new technologies such as StorageGRID launched by American NetApp Company, Vertica analysis platform released by Hewlett-Packard and Sybase IQ relational database developed by Sybase Company have brought technological innovation to the enterprise's big data analysis and processing and innovated the a new pattern of marketing big data technology for enterprise.

3) Implement accurate marketing of enterprises under the perspective of big data: In the era of data and information, consumers have full choice. Traditional marketing is an inaccurate marketing method. The marketing efficiency and success rate are not high. A product cannot meet the needs of all consumers. Only by accurately positioning customers, finding customers that match product positioning and accurately pushing products and services to target audiences, it can maximize marketing effectiveness; improve marketing efficiency and the profit of the company [6]. The core of precision marketing lies in "precision". The big data era provides powerful data resources for enterprises. Enterprises can use professional data storage, analysis, screening and presentation technologies to accurately measure and locate customers, can according to their individual needs design and deliver products, set acceptable prices, build convenient channels and accurately push and disseminate promotional information to improve own marketing performance.

\section{CONCLUSION}

In the context of big data, companies face as many opportunities and risks. Enterprise marketing innovation needs to be carried out at the level of concept, technology and application. Concept-level innovation can provide enterprises with new marketing thinking. Technology-level innovation can ensure the advanced nature of enterprise marketing technology and application-level innovation provides enterprises with more abundant marketing tools. Can be imagined, if a company can't grasp the new opportunities brought about by new technologies in time, innovate the ideas and behaviors of corporate marketing, it will lose more market opportunities in the future and will have to bear greater market competition and pressure. 


\section{REFERENCES}

[1] Junjie Zhang, Li Yang. Reform and Innovation of Marketing Portfolio Theory Based on Big Data Perspective[J].Commercial Economic Research,2015(5):54-55.(In Chinese)

[2] Jing Shu. Innovative research on corporate marketing model under the background of big data era [J]. Brand Research, 2018(4): 86-88. (In Chinese)

[3] Jieling Chen. Marketing change and innovation in the era of big data [J]. Business Economics Research, 2015(16): 48-49. (In Chinese)
[4] Wei Li, Xi Xiaotao. The value, foundation and direction of marketing innovation research in the era of big data [J]. Science and Technology Management Research, 2014(18): 181-184. (In Chinese)

[5] Jun Li. Actual combat in big data: customer positioning and precision marketing [M]. Beijing: Tsinghua University Press, 2015. (In Chinese)

[6] Chunfang Huang. On Enterprise Marketing Innovation in the Age of Internet Big Data [J]. Business Economics Research, 2018(14): 72-74. (In Chinese) 